\title{
VERIFICATION OF AN EFFECTIVE DOSE EQUIVALENT MODEL FOR NEUTRONS
}
J. E. Tanner
R. K. Piper
J. A. Leonowich
L. G. Faust

October 1991

\author{
Presented at the \\ 7 th Symposium on Neutron Dosimetry \\ October 14-18, 1991 \\ Berlin, Germany
}

Work supported by

the U.S. Department of Energy

under Contract DE-AC06-76RLO 1830

\author{
Pacific Northwest Laboratory \\ Richland, Washington 99352
}

\section{DISCLAIMER}

This report was prepared as an account of work sponsored by an agency of the United States Government. Neither the United States Government nor any agency thereof, nor any of their employees, makes any warranty, express or implied, or assumes any legal liability or responsibility for the accuracy, completeness, or usefulness of any information, apparatus, product, or process disclosed, or represents that its use would not infringe privately owned rights. Reference herein to any specific commercial product, process, or service by trade name, trademark. manufacturer, or otherwise does not necessarily constitute or imply its endorsement, recommendation, or favoring by the United States Governinent or any agency thereof. The views and opinions of authors expressed herein do not necessarily state or reflect those of the United States Government or any agency thereof 


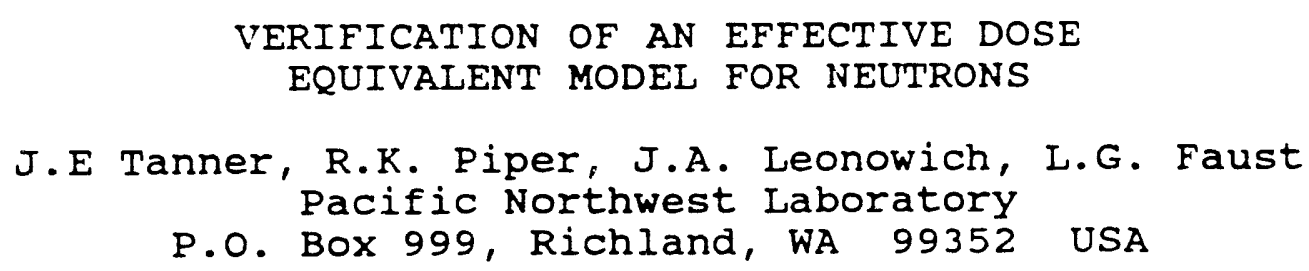

Abstract - since the effective dose equivalent, based on the weighted sum of organ dose equivalents, is not a directly measurable quantity, it must be estimated with the assistance of computer modeling techniques and a knowledge of the radiation field. Although extreme accuracy is not necessary for radiation protection purposes, a few well-chosen measurements are required to confirm the theoretical models. Neutron measurements were performed in a RANDO phantom using thermoluminescent dosemeters, track etch dosemeters, and a 1/2-in. $(1.27-\mathrm{cm})$ tissue equivalent proportional counter in order to estimate neutron doses and dose equivalents within the phantom at specific locations. The phantom was exposed to bare and $\mathrm{D}_{2} \mathrm{O}$-moderated ${ }^{252} \mathrm{Cf}$ neutrons at the Pacific Northwest Laboratory's Low Scatter Facility. The Monte carlo code MCNP with the MIRD-V mathematical phantom was used to model the human body and calculate organ doses and dose equivalents. The experimental methods are described and the results of the measurements are compared to the calculations. 


\section{INTRODUCTION}

The determination of effective dose equivalent, a concept ist introduced by the International Commission or Radiological protection (ICRP) (1) in 1977 , is required by most national and international authoritative bodies to show compliance with limits on worker exposure. The determination of effective dose equivalent requires a knowledge of the dose equivalent to certain organs which in most cases must be calculated and inferred from other measurements. Any calculational method used to determine radiation exposure must be shown through measurements to be as accurate as current technology allows; this has been fairly straightforward for photons but has proved to be much more difficult for neutrons. The objective of this study was to identify and perform the measurements necessary to verify the calculational models used at the Pacific Northwest Laboratory (PNL) in support of implementing effective dose equivalent.

For the verification measurements, simple exposure conditions were deemed necessary. A 252 Cf source was used for its traceability to the National Institute of standards and Technology (NIST) and simple point source geometry. Measurements were performed with the bare ${ }^{252} \mathrm{Cf}$ source and with the source in the 15-cm-radius, cadmium-covered $\mathrm{D}_{2} \mathrm{O}$ sphere. The goal was to show that the calculated organ doses agreed with the measured organ doses to within $20 \%$. This is based on predicted measurement errors of $10-15 \%$ and statistical errors of $5-10 \%$ in the calculations. Based on the accuracy and precision of current neutron dosemeters, this was considered acceptable. 


\section{NEUTRON CALCULATIONAL MODEL}

The calculations were based on the Monte Carlo general - se radiation transport code, MCNP, developed by Los Alamos National Laboratory. (2) Continuous-energy neutron cross sections from the Evaluated Nuclear Data File $B-V$ (ENDF/B-V) were used in the transport calculations, along with the MIRD-V mathematical anthropomorphic phantom. (3) The source terms were modeled as isotropic point sources with a watt fission energy spectrum describing the bare ${ }^{252} \mathrm{Cf}$ source and the Iso energy histogram for the $\mathrm{D}_{2} \mathrm{O}$-moderated $252 \mathrm{Cf}$ source.

The MCNP code calculates the energy-dependent fluences and absorbed doses to specified organs from neutrons and neutroninduced photons due to neutrons incident uniformly on the surface of the phantom. A post-processing code is necessary to read the output from an MCNP calculation and apply the appropriate quality factors and weighting factors to result in a single number for the effective dose equivalent per unit incident fluence. The main focus was to verify the Monte Carlo technique and input parameters that result in estimates of the organ doses.

\section{NEUTRON MEASUREMENTS}

All measurements were performed in PNL's Low-Scatter Facility with a RANDO Average-Man phantom and a $1.47-\mathrm{mg} 252 \mathrm{Cf}$ neutron source. The RANDO phantom is composed of Aiderson Muscle tissue substitute material molded about an actual human skeleton with $5 \mathrm{~mm}$ diameter holes drilled in a $3-\mathrm{cm}-\mathrm{x}-3-\mathrm{cm}$ array for holding dosemeters. These holes are filled with tissue- 
equivalent (TE) plastic plugs when not being used. The phantom consists of 36 separate slices, 1 in. $(2.54 \mathrm{~cm})$ thick, numbered 0 to 35. During the exposures, the distance from the source to the front surface of the phantom at mid-torso height (slice 21) was 1 meter. Figure 1 shows the phantom set up at 1 meter from the source. One disadvantage of using a RANDO phantom is the fact that although it's torso and head dimensions are very realistic, it has no arms or legs as seen in Figure 1.

The criteria used for selecting a measurement technique for this study were 1) sensitivity to neutrons, 2) accuracy over neutron energies from thermal to $10 \mathrm{MeV}, 3)$ small enough to fit at a point of interest inside a physical phantom without perturbing the flux, and 4) exhibiting little or no directional dependence to complicate interpretation of results.

An initial measurement was perforwed with thermoluminescent dosemeters (TLDS) and track etch dosemeters (TEDs) because of their small size and availability. The TLDs consisted of ${ }^{7}$ LiF chips used in conjunction with ${ }^{6}$ LiF chips to correct for the gamma component of the response. Sets of chips were also exposed bare and covered with cadmium to attempt to distinguish between the thermal and fast neutron components. The track etch dosemeters $(C R-39), 2.86 \mathrm{~cm} \times 1.59 \mathrm{~cm} \times 0.635 \mathrm{~mm}$, were placed horizontally between phantom slices. In this initial set, only four organs were chosen for preliminary characterization due to the large effort involved in the data processing and analysis. The locations of the specific holes and slices corresponding to a particular organ were based on the previous work by Huda and 
Sandison(4) and Golikov and Nikitin(5). Also, since only one TLD element, bare or cadmium-covered, could be accommodated in one the bare and cadmium-covered elements were staggered, with a TED between.

The results of the measurements and calculations for the thyroid, heart, liver, and kidneys are shown in Table 1 for the bare ${ }^{252} \mathrm{Cf}$ exposure. The phantom was exposed to the bare source for 10.86 minutes for a reference dose equivalent of $5.0 \mathrm{mSv}$ at 1 meter. Table 2 shows the results for the $\mathrm{D}_{2} \mathrm{O}$ moderated $252 \mathrm{Cf}$ exposure. The phantom was exposed to the moderated source for 69.32 minutes for a reference dose equivalent of $7.5 \mathrm{mSv}$ at 1 meter. The results varied significantly due to the difficulty in calibrating the TLD chip response for the correct neutron energies and the angular dependence and energy threshold of the TEDS.

Because of the poor correlations obtained with the TLDs and TEDs in the phantom, a $1 / 2-i n .(1.27-\mathrm{cm})$ tissue-equivalent proportional counter (TEPC) was used to obtain a direct measurement of the absorbed neutron dose within the phantom. The TEPC used was a $1 / 2 \mathrm{in.}(1.27 \mathrm{~cm})$ diameter tissue-equivalent (TE) sphere enclosed in a cylindrical aluminum housing at the end of a long aluminum stem. A schematic of the detector is shown in Figure 2. The sphere was filled with propane TE gas at a pressure of 33.4 torr to simulate a $1 \mu \mathrm{m}$ site of tissue. To avoid drilling large holes in the RANDO phantom to accommodate the TEPC, a 1-in. $(2.54-\mathrm{cm})$ thick slab of polyethylene in the cross-sectional shape of the phantom torso was substituted for an 
actual slice in the phantom at several different measurement positions. The polyethylene slice had a 3/4-in. (1.9-cm) hole trilled through from the back of the torso to the middie of the slice. The TEPC was inserted from the back into the phantom in this way and the center of the TEPC's active volume was in the center of the substitute slice. Pulse height distributions were collected on a multichannel analyzer during the measurements and stored in computer files. The raw data was analyzed with the computer code, tepc_ng, written at PNL. (6)

Measurements were attempted at three different elevations within the phantom torso. Although the outer shape of the torso changes with elevation, the front of the substitute slice was always flush with the front of the surrounding torso slices and the distances from the center of the detector to the front of the torso and to the source were carefully measured and recorded. The measurements were performed at slices 11, 21, and 31 with the phantom exposed to both bare and $\mathrm{D}_{2} \mathrm{O}$-moderated $252 \mathrm{CF}$.

For the purpose of comparing the calculated absorbed dose to the measured absorbed dose, the mathematical phantom was modified to include a model of the TEPC inside the phantom in place of tissue/organ material. The TEPC was modeled as a $1.27 \mathrm{~cm}$ inside diameter, A-150 TE plastic sphere, $0.127 \mathrm{~cm}$ thick with the TE gas inside and outside the sphere but inside the $1.9-\mathrm{cm}$-diameter aluminum housing. The aluminum itself was not modeled because of its transparency to neutrons. Figure 3 shows the mathematical model as drawn by the MCNP code. The phantom composition was also changed from ICRP tissue $(10.47 \% \mathrm{H}, 23.02 \% \mathrm{C}, 2.34 \% \mathrm{~N}$, 
$63.21 \%$ O) to Alderson Muscle $(8.8 \% \mathrm{H}, 64.4 \% \mathrm{C}, 4.1 \% \mathrm{~N}, 20.4 \%$

0) (7) and the legs were deleted several inches below the torso to

$\because$ the actual RANDO phantom. Instead of calculating organaveraged fluences, a calculation of the energy deposited in the active volume of the detector was performed to compare to the absorbed dose measured by the TEPC. The results of the TEPC measurements and calculations are compared in Table 3 .

\section{CONCLUSIONS}

The measurements and calculations agreed within the $20 \%$ criterion for verification of this technique. It is assumed that a correct estimation of the absorbed dose at these locations within the phantom translates into correct estimations of absorbed doses at organ locations. After careful studies of the precision of the measurements and the low statistical errors associated with the calculations, the observed differences can be attributed to the differences still remaining between the physical phantom and the mathematical phantom, which although not trivial, are also typical of the differences one might find between body types.

These results allow us to proceed to model more complex exposure situations in the future such as different sizes of phantoms and nonuniform geometries. The same organ doses have also been used to estimate the new ICRP $60^{(8)}$ quantity, effective dose, and compare that to effective dose equivalent. 


\section{REFERENCES}

1 TCRP, International Commission on Radiological Protection. Recommendations of the International Commission on Radiological Protection. Publication 26. Ann. ICRP 1(3) (Oxford: Pergamon Press) (1977).

2. MCNP - A General Monte Carlo Code for Neutron and Photon Transport. Version 3A. LA-6396-M, Revision 2. September 1986, MCNP3B Newsletter (July 1988).

3. Medical Internal Radiation Dose (MIRD) Pamphlet No. 5, Revised (1978). Estimates of Specific Absorbed Fractions for Photon Sources Uniformly Distributed in Various organs of a Heterogeneous Phantom. G. G. Society of Nuclear Medicine, New York.

4. Huda, W. and Sandison, G. A. Estimation of Mean Organ Doses in Diagnostic Radiology from Rando Phantom Measurements. Health Physics $47(3), 463-467$ (1984).

5. Golikov, V. Y. and Nikitin, V. V. Estimation of the Mean Organ Doses and the Effective Dose Equivalent from Rando Phantom Measurements. Health Physics 56(1), 111-115 (1989).

6. Brackenbush, L. W., stroud, C. M., Faust, L. G., and Vallario, E. J. Personnel Neutron Dose Assessment Upgrade - Volume 2: Field Neutron Spectrometer for Health Physics Applications. PNL6620 Vol. 2 (Richland, WA: Pacific Northwest Laboratory) (1988). 
7. ICRU, International Commission on Radiation Units and Measurements. Tissue Substitutes in Radiation Dosimetry and Massuremnnt Report 44 (Bethesda,MD: ICRU Publications) (1989).

8. ICRP, International Commission on Radiological Protection. Recommendations of the International Commission on Radiological Protection. Publication 60. Ann. ICRP 21(1-3) (Oxford: Pergamon Press) (1990). 
Table 1. Organ Doses for Bare ${ }^{252} \mathrm{Cf}$ (mSv)

TEDS

Thyroid

Heart

Liver

Kidneys
0.960

0.693

0.880

0.360 $\underline{\text { TLDS }}$

4.240

5.694

3.506

2.366
Calculated

3.555

2.375

2.264

0.599

Table 2. Organ Doses for $\mathrm{D}_{2} \mathrm{O}$ Moderated $252 \mathrm{Cf}$ (mSv)

\section{organ}

Thyroid

Heart

Liver

Kidneys

\section{TEDS}

1.710

1.370

1.365

0.320

\section{TLDS}

3.980

1.782

1.537

0.610
Calculated
4.836
3.650
3.274
0.885 
Table 3. Absorbed Doses for Bare and $D_{2} \circ$ Moderated $252 \mathrm{Cf}$ (mGy/h)

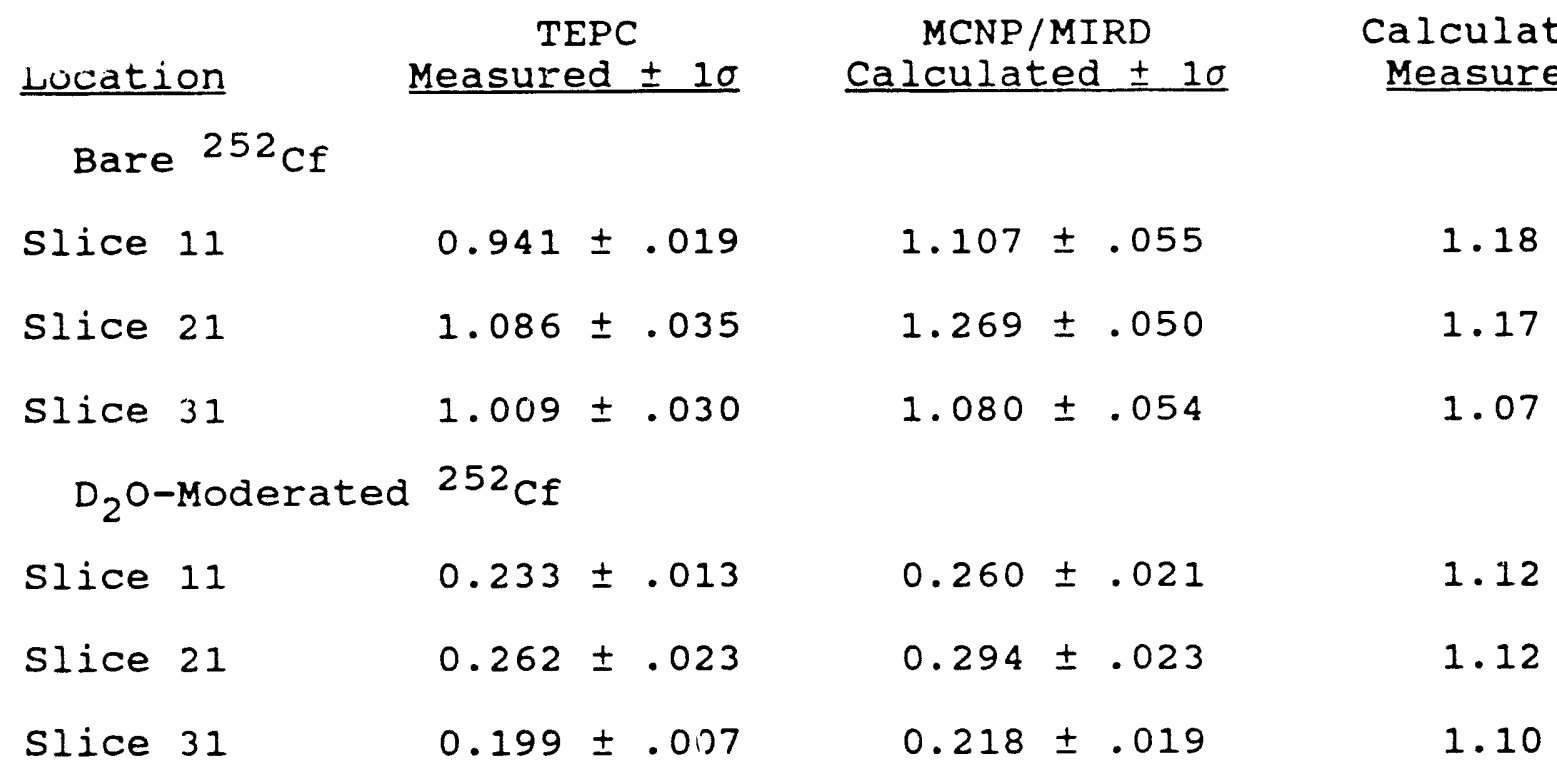




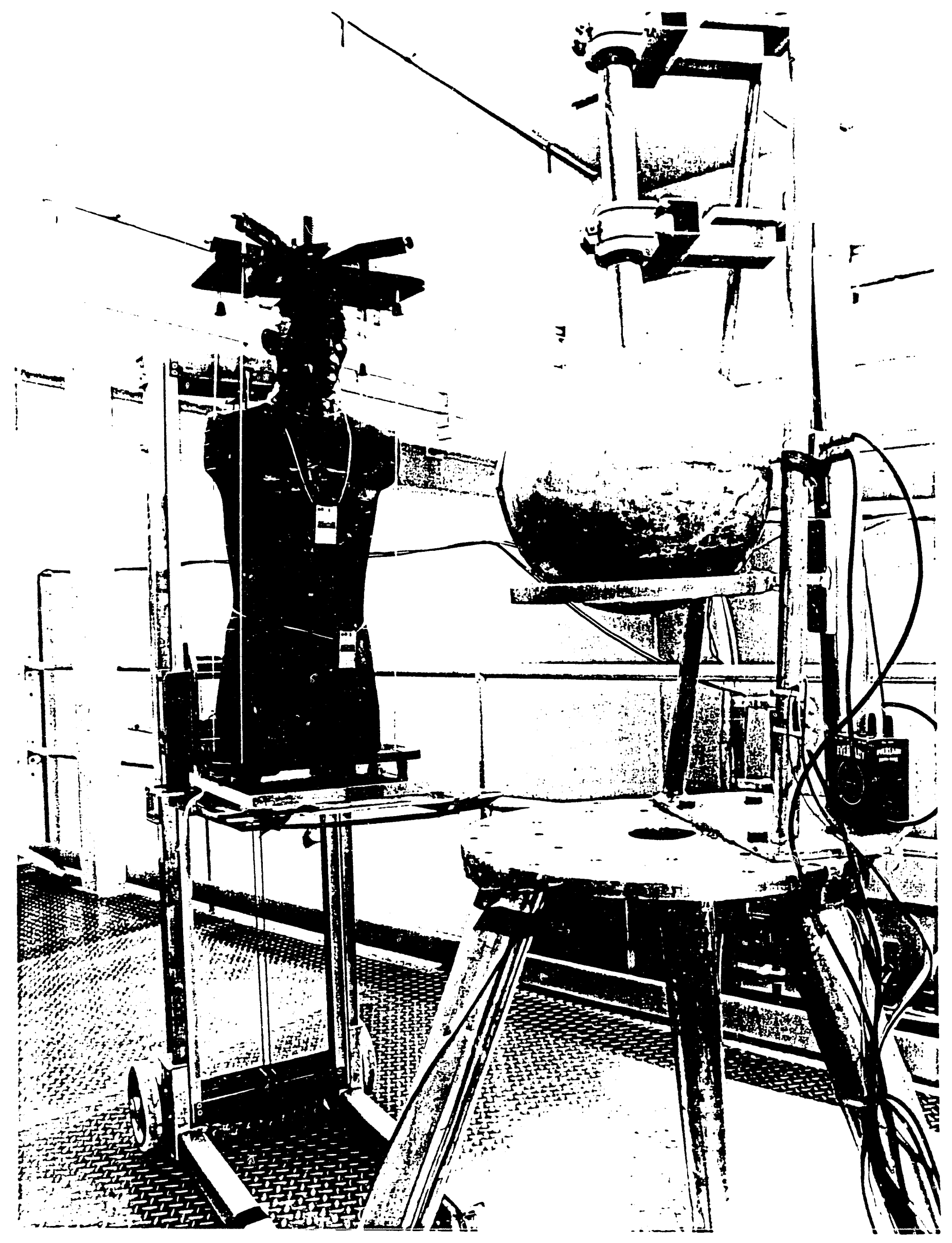


1/2 - Inch Tissue-Equivalent Proportional Counter

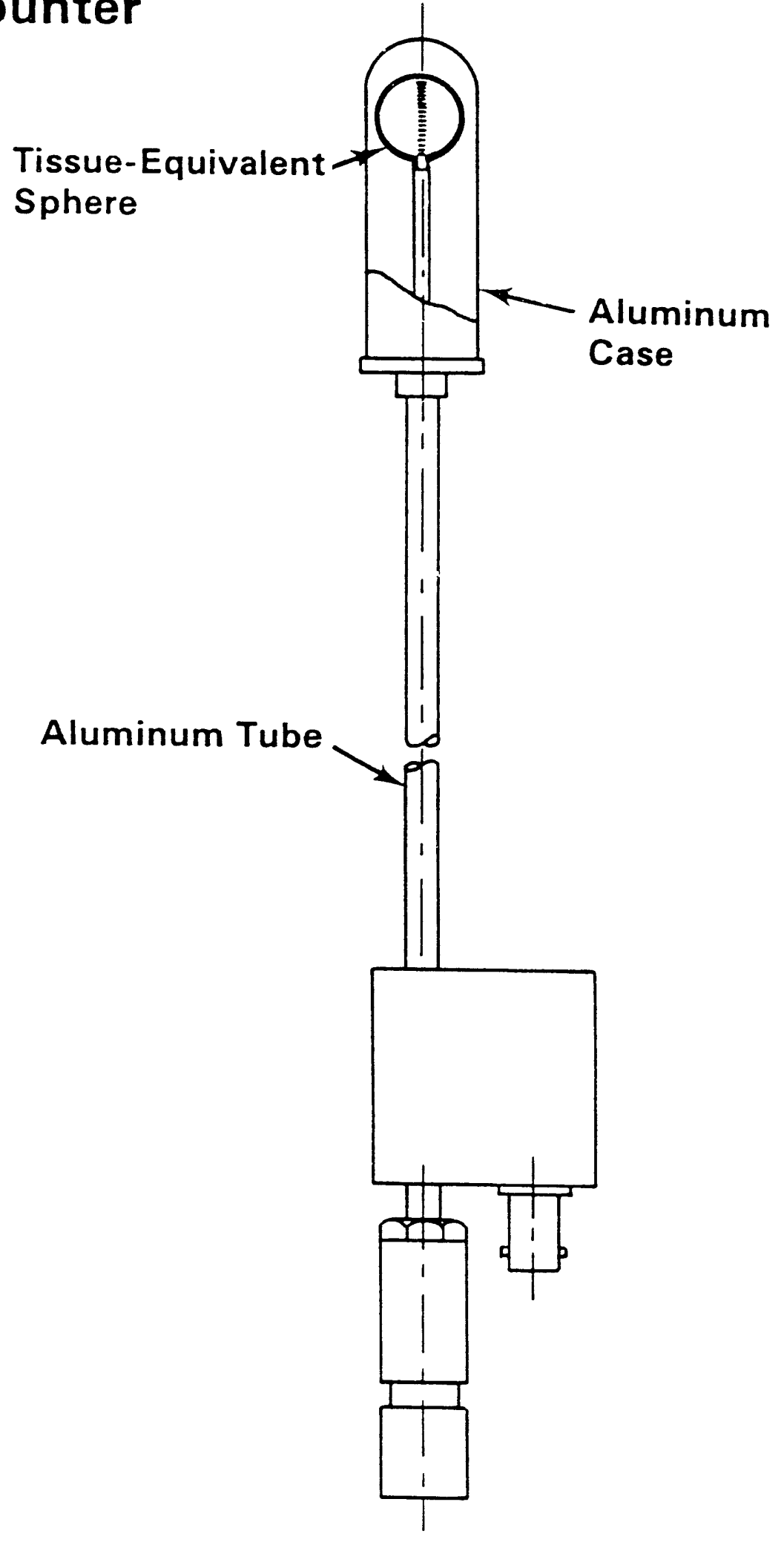



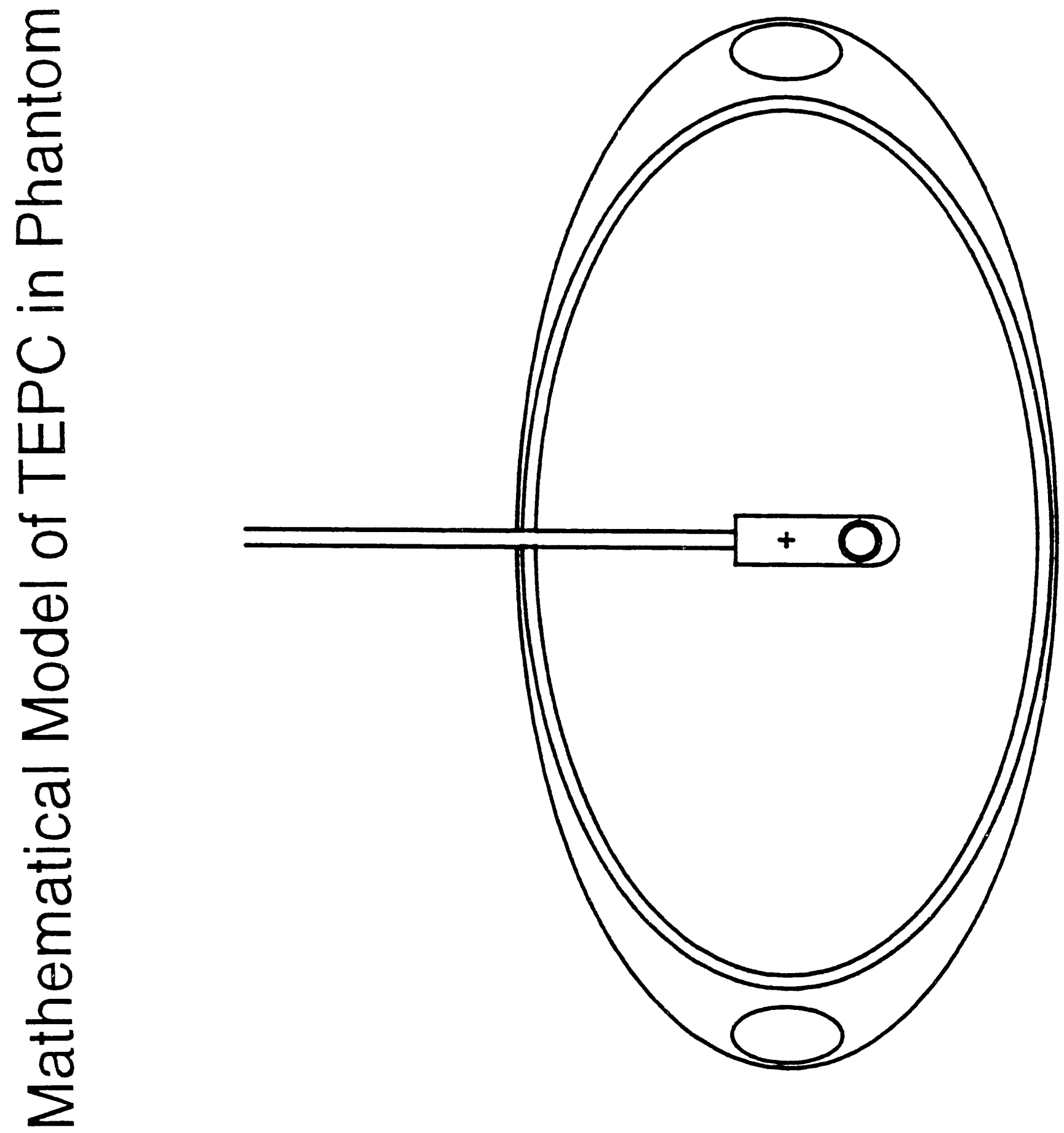

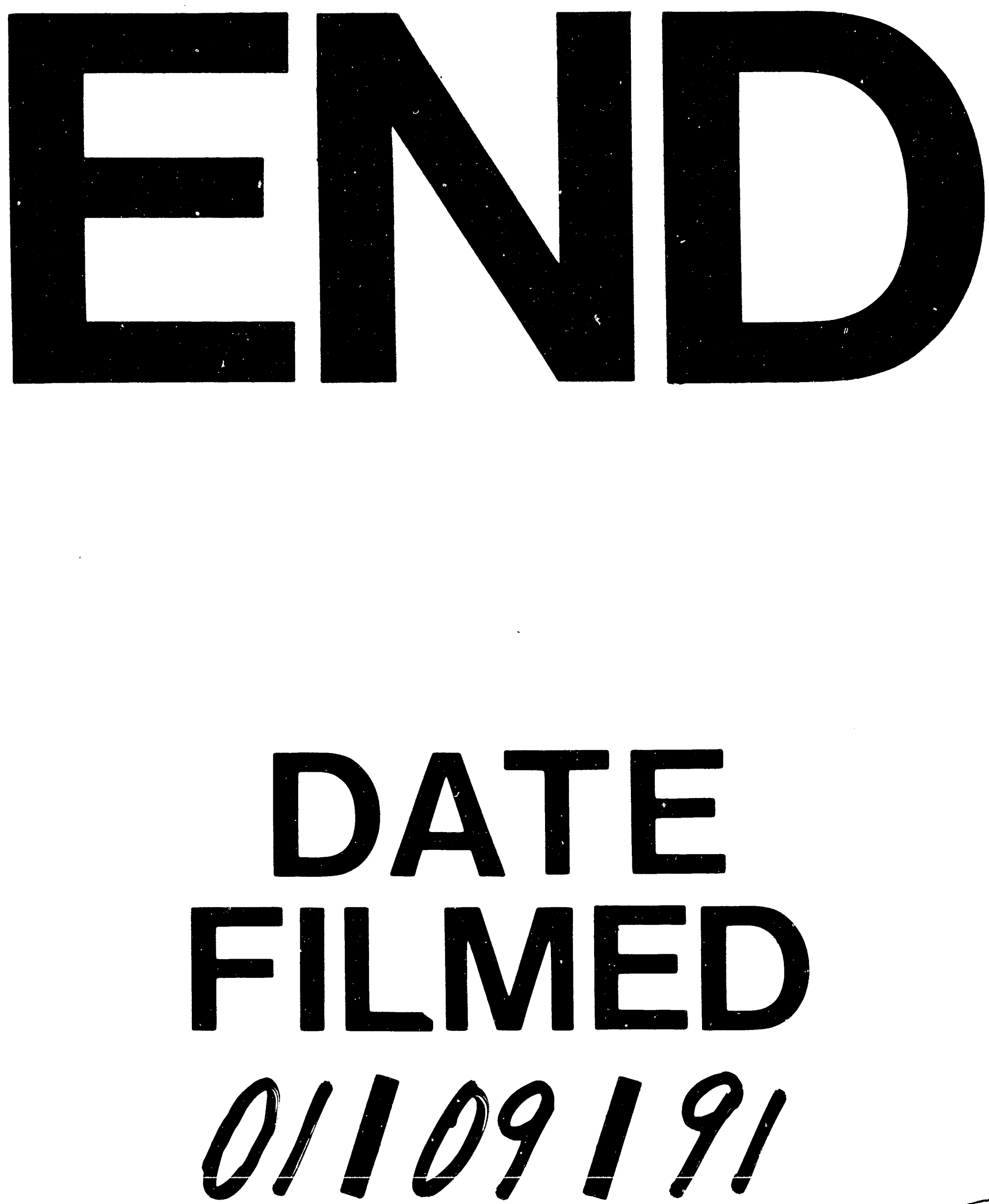
